\title{
ABORDAGEM FAMILIAR NO CONTEXTO DA ESTRATÉGIA DE SAÚDE DA FAMÍLIA
}

\author{
FAMILY APPROACH IN THE CONTEXT OF THE FAMILY HEALTH STRATEGY \\ Paloma Natal Teixeira, Nicolle Silva Lopes de Brito, Jamile Pereira Dias dos Anjos, Raquel \\ Sousa Leite Aguiar
}

Universidade Estadual De Montes Claros - Unimontes

\begin{abstract}
This is a qualitative study, carried out in the second half of 2018 and the first semester of 2019, with a family residing in the area of coverage of a Family Health Strategy, through the application of the tools: genogram, FIRO, PRACTICE, family life cycle and semi structured interview, with the purpose of reporting the experience of health professionals of the Family Health Strategy team of the city of Montes Claros, Minas Gerais, regarding the application of family approach tools as part of the situational diagnostic process of a family registered in the area of coverage of the health team. Through the application of the tools there was better access of the team to the family, facilitating the family reorganization, as well as dialogue and intrafamiliar communication. Therefore, the family study allowed the strengthening of ties between the team and its users, favoring the effectiveness of the intervention.
\end{abstract}

Key words: Health Care; Family; Family Health Strategy.

\section{Resumo}

Trata-se de um estudo de abordagem qualitativa, realizado no segundo semestre de 2018 e primeiro semestre de 2019, com uma família residente na área de abrangência de uma Estratégia de Saúde da Família, através da aplicação das ferramentas: genograma, F.I.R.O., P.R.A.C.T.I.C.E., ciclo de vida familiar e entrevista semiestruturada, com o objetivo de relatar a vivência de profissionais de saúde da equipe de Estratégia Saúde da Família do município de Montes Claros, Minas Gerais, quanto à aplicação das ferramentas de abordagem familiar como parte do processo diagnóstico situacional de uma família cadastrada na área de abrangência da equipe de saúde. Através da aplicação das ferramentas houve melhor acesso da equipe à família, facilitando a reorganização familiar, bem como diálogo e comunicação intrafamiliar. Portanto, o estudo da família possibilitou o fortalecimento de vínculos entre a equipe e seus usuários, favorecendo a eficácia da intervenção.

Palavras chave: Atenção à Saúde; Família; Estratégia Saúde da Família. 


\section{Introdução}

A Estratégia Saúde da Família (ESF) surgiu em 1994 com o objetivo de reorganização do Sistema Único de Saúde (SUS) e de contrapor-se ao modelo biomédico de atenção à saúde, até então hegemônico, que privilegiava a doença e o individual ao invés do coletivo ${ }^{1}$. Para tal as ações da ESF devem ser estruturadas no trabalho em equipe e buscar humanizar as práticas de saúde através da aplicação dos princípios do SUS, dos quais destacam-se a integralidade e a participação da comunidade. Com isso busca-se obter a satisfação do usuário por meio do estreito relacionamento dos profissionais com a comunidade a fim de reconhecer e atender suas necessidades, além de envolvê-la no processo de cuidado $^{2}$.

Nesse contexto, abordar a família como centro do cuidado da Atenção Primária à Saúde é uma situação prioritária, especialmente se a colocamos na estratégia de reorganização do sistema de saúde. Logo, é essencial conhecer as configurações, arranjos e contexto em que essa família se insere a fim de compreendê-la como unidade de produção social e fator determinante do processo saúde-doença de seus membros ${ }^{3}$.

$\mathrm{Na}$ família desenvolvem-se estratégias de sobrevivência para o presente, constroem-se projetos futuros e avalia-se o passado. As práticas de cuidado à saúde, as crenças e os valores atribuídos às atitudes e aos comportamentos como hábitos alimentares, atividade física, lazer, uso de substâncias, como o tabaco e o álcool são vivenciados e aprendidos na família ${ }^{1}$. Assim sendo, o conjunto familiar apresenta-se como uma dimensão importante a ser considerada na busca de compreensão da forma que o sujeito se relaciona com seu contexto real de vida ${ }^{4}$.

Nesse intuito de construir uma prática inovadora e contra-hegemônica capaz de oferecer uma assistência integral ao indivíduo, articulada ao contexto familiar e comunitário, é necessário que a ESF crie um ambiente no qual profissionais e famílias possam estabelecer uma relação de parceria, confiança, comunicação e transparência, bem como cooperação, de tal forma que atenda às necessidades da família ${ }^{1,5}$. Para tanto, torna-se pertinente no âmbito da atenção primária o estudo da família através da utilização de instrumentos que possibilitem conhecer sua composição, funcionamento e estrutura, além dos problemas de saúde, situações de risco e os padrões de vulnerabilidade, considerando as especificidades de cada grupo familiar no planejamento das ações de cuidado à saúde ${ }^{4}$.

O trabalho com a família deve envolver um completo entendimento e uma extensa avaliação clínica e psicológica de seus membros, o que se faz através da utilização de ferramentas de abordagem familiar, que facilitarão a compreensão na formulação de um diagnóstico que possibilitará uma intervenção eficiente. Dentre as várias ferramentas existentes, tem-se: o Genograma; Ciclo de vida; P.R.A.C.T.I.C.E; F.I.R.O e por fim, a Conferência Familiar ${ }^{6}$.

Considerando a família como fator determinante do processo saúde-doença de seus membros através de todas as suas interações e contexto econômico e sócio-cultural, esse trabalho se justifica pelo seu potencial em fornecer um atendimento integral e intervenção eficaz sobre os fatores de risco e problemas identificados na família selecionada.

Assim, o presente trabalho objetiva relatar a vivência de profissionais de saúde (médica, enfermeira e cirurgiã-dentista) da equipe de uma Estratégia Saúde da Família do município de Montes Claros, Minas Gerais, quanto à aplicação de ferramentas de abordagem familiar como parte do processo diagnóstico situacional de uma família cadastrada na área de abrangência da equipe de saúde.

\section{Metodologia}

Trata-se de um estudo de abordagem metodológica qualitativa, realizado por uma Equipe Multiprofissional de Saúde da Família, com um núcleo familiar residente no território de abrangência da referida equipe.

Este foi desempenhado no segundo semestre de 2018 e primeiro semestre de 2019 pelas profissionais Médica (integrante do Programa de Residência Médica em Medicina de Família e Comunidade da Universidade Estadual de Montes Claros-MG), Enfermeira e CirurgiãDentista (integrantes do Programa de Residência Multiprofissional em Saúde da Família da Universidade Estadual de Montes Claros-MG).

A família selecionada para este estudo é cadastrada em uma ESF, localizada na cidade de Montes Claros-MG e foi escolhida por apresentar queixas e demandas de assistência frequentes. Para a intervenção familiar foram realizados 04 encontros na residência da família e na Unidade Básica de Saúde (UBS), pelas profissionais: enfermeira, médica e cirurgiã-dentista.

A coleta de dados foi realizada através da aplicação das ferramentas de abordagem familiar (Genograma, O Ciclo de Vida das Famílias, Fundamental Interpersonal Relations Orientation 
(FIRO), Problem, Roles, Affect, Communication, Time, Illness, Coping, Ecology (P.R.A.C.T.I.C.E) e Conferência Familiar) e entrevistas semiestruturadas, na UBS e durante visitas domiciliares.

O Genograma é um método que armazena informações sobre a composição familiar e os relacionamentos básicos em, pelo menos, três gerações, representados através de símbolos. De uma forma mais prática, contempla quais são os membros constituintes da família, tendo eles vínculos consanguíneos ou não, identificando-os também pela idade, condição de saúde e retratando o lugar ocupado por cada um dentro do ambiente familiar? ${ }^{7}$.

O Ciclo de Vida Familiar é compreendido como movimentos e alterações que ocorrem ao longo da história familiar, apresentando padrões de relativa previsibilidade, constituindo-se em estágios de desenvolvimento e exigindo adaptação e ajustamento de seus membros ${ }^{8}$.

A ferramenta Fundamental Interpersonal Relations Orientations (FIRO) busca compreender as relações de afeto, trocas comunicativas e estabelecimento de poder dentro do contexto familiar. Essas relações interpessoais familiares podem ser representadas por três dimensões: inclusão (interação dentro da família); controle (interações do exercício de poder dentro da família); intimidade (o modo como os sentimentos são compartilhados nas interações familiares). Assim procura-se avaliar as alterações familiares diante dos ciclos de vida familiar e no surgimento de patologias graves ${ }^{6}$.

$O$ instrumento P.R.A.C.T.I.C.E. constitui o acróstico de (Problem, Roles, Affect, Comminication, Time oflifecycle, Illness, Coping, Ecology), sendo utilizado em situações familiares mais complexas, permitindo a avaliação do funcionamento familiar e a elaboração de um projeto de intervenção com os dados fornecidos pela família com foco no problema apresentado. Cada letra traz consigo um significado, sendo estes: $P$ - refere-se à percepção da família diante do problema; $R$ - descreve os papéis de cada membro; $A$ - como são estabelecidas as trocas de afetos; $C$ - identifica a comunicação verbal e não verbal na família; $T$ - estabelece a passagem do ciclo de vida; I - resgata o histórico de morbidade familiar; $C$ - diz respeito aos recursos familiares para lidar com o problema; $E$ - trata dos recursos externos disponíveis que podem ser mobilizados para a superação do problema ${ }^{9}$.

Já a Conferência familiar é entendida como a possibilidade de, mediante uma reunião com os membros familiares, abordar a situaçãoproblema e orientar a família sobre como manejar a situação. Esta permite que sejam expressos e compartilhados os sentimentos e percepções dos membros familiares sobre a situação vivenciada, facilitando a troca comunicativa e entendendo como cada um pode contribuir na resolução do problema ${ }^{10}$.

A presente investigação foi conduzida seguindo os requisitos exigidos pela resolução do Conselho Nacional de Saúde $N^{\circ}$ 466, de 12 de dezembro de 2012, que trata de pesquisa envolvendo seres humanos e recebeu aprovação pelo Comitê de Ética em Pesquisa da Universidade Estadual de Montes Claros (UNIMONTES), sob o parecer de número 572244 de 27 de março de 2014. Os familiares consentiram em participar do estudo por meio do Termo de Consentimento Livre e Esclarecido. Para resguardar os sujeitos envolvidos, optou-se pela utilização de nomes fictícios.

\section{Resultados e Discussão}

\section{Caracterização da Família}

A família escolhida para esse estudo foi a de Rosa (paciente índice), 53 anos, nascida em Montes Claros, casada, católica, ensino médio completo, desempregada há 10 anos e residente no município de Montes Claros. Portadora de Hipertensão Arterial Sistêmica (HAS) e depressão.

Reside em casa própria de boa estrutura física com o esposo Luiz, 53 anos, representante comercial, ensino médio completo e com histórico de HAS, com quem casou-se aos 23 anos de idade e relata situação conjugal harmoniosa. Dessa união, tiveram duas filhas: Liz, atualmente com 24 anos e Luna, 17 anos, ambas residem com os pais e são portadoras de Transtorno de Ansiedade Generalizada (TAG).

O pai de Rosa, Aldo, etilista, portador de Insuficiência Cardíaca Congestiva (ICC) faleceu aos 87 anos, devido complicações de pneumonia, também causa da morte da mãe, Eva, que veio a óbito aos 86 anos. O casal teve 14 filhos, dos quais 9 são vivos e 5 falecidos, e apresentam como principais comorbidades: transtornos mentais, Diabetes Mellitus (DM), HAS e alcoolismo.

A busca pela ESF, iniciou-se em 2015, quando a paciente procurou o serviço no mês de setembro com queixa de mastalgia, retornando ao serviço em dezembro do mesmo ano relatando crises frequentes de ansiedade, sendo medicada e encaminhada para terapia com a psicóloga. Durante tais atendimentos outras demandas foram surgindo, da paciente e seus familiares, como tratamentos odontológicos, 
consultas com clínico geral, consultas com a psicóloga e de enfermagem. A partir deste momento, foram sendo constituídos vínculos com os profissionais da equipe de saúde e a família.

Com o acompanhamento contínuo dos membros familiares na ESF, alguns dos problemas foram resolvidos, porém a paciente permanecia com queixas frequentes de inutilidade, culpa e desestruturação familiar.

Em consequência, a equipe se reuniu para discutir o caso, buscando uma melhor abordagem para a assistência e resolução de problemas da paciente, percebendo que a intervenção familiar seria a melhor escolha.

\section{Genograma}

$\mathrm{Na}$ Figura 1, está representado o genograma da família de Rosa, apresentada em três gerações, no qual se pode perceber a frequência das doenças DM, HAS, depressão e alcoolismo ao longo das gerações.

Figura 1. Genograma da família em estudo

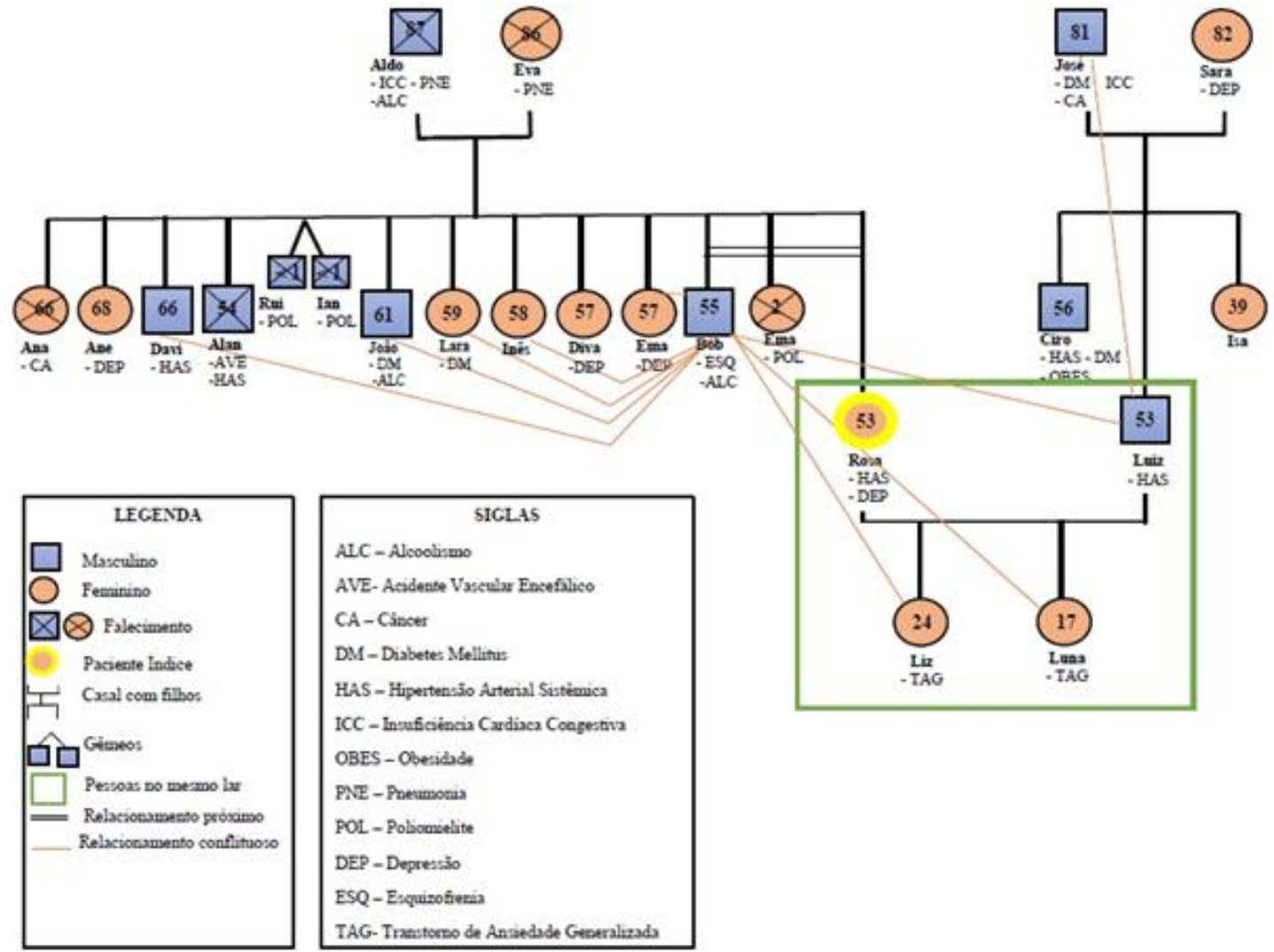

Fonte: Elaborado pelos autores

O processo de construção do genograma permitiu explorar características biológicas, genéticas e comportamentais que afetam a estrutura familiar e suas relações, mostrando repetições nos padrões do estilo de vida que levam a essas comorbidades. Pode-se perceber, ainda, a existência de relação conflituosa entre o irmão de Rosa, Bob, com seu cunhado e sobrinhas.

\section{Ciclo de vida}

Em relação à classificação da família no ciclo de vida, a família encontra-se no estágio "Famílias com adolescentes" e "Casais de meia idade". Tais estágios justificam-se pela necessidade de equilibrar as relações organizacionais, as quais interferem nos papéis exercidos por cada membro da família. Principalmente em se tratando das filhas que, com o início da vida adulta e final da infância, não conseguem equilibrar a liberdade com responsabilidade à medida que vão adquirindo individualidade e autonomia. Isso também se aplica à paciente índice, que apesar de sentir-se responsável pela dependência das filhas em 
relação a ela, não contribui para que esse sentimento seja superado.

FIRO

O instrumento FIRO, do inglês Fundamental Interpersonal Relations Orientations, foi utilizado para uma maior compreensão da dinâmica familiar, sendo este, categorizado nas dimensões de Inclusão, Controle e Intimidade, ou seja, a família pode ser estudada quanto às suas relações de poder, comunicação e afeto.

Inclusão: na divisão de papeis, Rosa é a chefe de família, responsável pela dinâmica familiar e tarefas domésticas do lar, no entanto, sente falta da independência financeira que tinha quando estava no mercado de trabalho; Luiz se apresenta como provedor financeiro, porém pouco se envolve nas questões familiares pois permanece maior tempo fora de casa devido as atividades laborais; Liz é responsável pela contabilidade da casa e se sente deslocada por ser recém-formada e encontrar dificuldade para inserir-se no mercado de trabalho; Luna cumpre poucas funções no cotidiano familiar, pois permanece maior tempo na escola, sendo responsável apenas por alimentar os animais e realizar pequenas atividades no lar.

A sensação de inutilidade de Rosa e o desejo de regressar ao mercado de trabalho, é evidenciado através das falas:

"Meu papel mudou depois que saí do emprego, uma vez que desde os 18 anos eu trabalhava na área administrativa, ocupando um cargo de responsabilidade e influência". (Rosa)

"O papel da família mudou, no sentido que antes minhas filhas eram mais independentes $e$ agora se desligaram de suas funções, se apoiando mais em mim". (Rosa)

Todavia, na visão de Liz e Luna, a mudança nos papéis familiares após a saída da mãe do emprego se mostra como vantajoso, fato demonstrado através das falas:

"Minha mãe não trabalhar foi a melhor coisa que aconteceu". (Luna)

Controle: Em relação ao processo de decisão observa-se que o controle é dominante, uma vez que a paciente índice determina a maioria das decisões da família e há aceitação dos demais membros. Fato que pode ser visto através das falas:
"Tenho voz decisória e sempre foi assim". (Rosa)

"Minha mãe tem tanta influência na casa que até o humor dela, influencia no humor da família. Se ela acorda feliz, todos vão ter um bom dia e se ela não acordar bem, o dia não segue bem." (Liz)

Intimidade: No que se refere ao afeto e intimidade, a família de modo geral possui união e bom relacionamento entre todos os residentes do lar. A paciente índice relata que os conflitos da família são resolvidos através do diálogo. No entanto, apesar de não residir no mesmo local que a família a proximidade do relacionamento entre Rosa e seu irmão Bob que possui esquizofrenia e histórico de alcoolismo, gera um conflito familiar e é motivo de muitas discussões da paciente índice com suas filhas e esposo. É perceptível essa relação de conflito na fala de Rosa e Liz:

"Estou satisfeita em relação ao afeto, pois amo todos! Porém Bob é motivo de conflito na família." (Rosa)

"Eu sei que meu tio precisa de ajuda, mas é papel dos meus outros tios também ajudarem. Ele está tão acostumado com a situação que qualquer motivo recorre a minha mãe." (Liz)

É possível observar um certo distanciamento do esposo Luiz em relação à resolução de conflitos. Todavia, em sua fala Rosa refere que o marido traz segurança e participa da resolução de problemas mesmo à distância, ao mesmo tempo que diz omitir algumas dificuldades para não o preocupar.

"O Luiz é pés no chão, o que traz sensação de tranquilidade e segurança na família. Minhas filhas ouvem mais o pai." (Rosa)

"Meu esposo percebe quando tem problema, mas eu não me abro, pois não quero encher a cabeça dele com problemas e nem me mostrar fraca para as minhas filhas." (Rosa)

\section{P.R.A.C.T.I.C.E.}

Conforme visualizado no Quadro 1, pode-se observar a descrição da aplicação da ferramenta P.RA.T.I.C.E. nas dimensões: problemas apresentados, papéis, afeto, comunicação, tempo no ciclo de vida familiar, doenças no 
passado e no presente, lidando com o estresse e ecologia ou meio ambiente.

Quadro 1. Descrição da aplicação da ferramenta P.RA.T.I.C.E. na família em estudo.

\begin{tabular}{|c|c|}
\hline \multicolumn{2}{|r|}{ P.R.A.C.T.I.C. E. } \\
\hline $\begin{array}{l}\text { Problemas } \\
\text { Apresentados } \\
\text { (Problems) }\end{array}$ & $\begin{array}{l}\text { - Foi identificado como conflito familiar o não compartilhamento dos cuidados } \\
\text { de Rosa em relação a Bob com os demais irmãos; } \\
\text { - Percebeu-se ainda que a dependência das filhas em relação a mãe também é } \\
\text { visto como problema, principalmente no que diz respeito à superação do ciclo } \\
\text { de vida familiar; } \\
\text { - Rosa não compartilhar responsabilidades referentes à resolução de } \\
\text { problemas com o esposo; } \\
\text { - Rosa não conseguir reinserção no mercado de trabalho. }\end{array}$ \\
\hline Papéis (roles) & $\begin{array}{l}\text { - Rosa é chefe de família, responsável pela dinâmica familiar e tarefas } \\
\text { domésticas do lar, no entanto, sente falta da independência financeira que } \\
\text { tinha, quando estava no mercado de trabalho; } \\
\text { - Luiz se apresenta como provedor financeiro, porém pouco se envolve nas } \\
\text { questões familiares por permanecer maior tempo fora de casa devido as } \\
\text { atividades laborais; } \\
\text { - Liz é responsável pela contabilidade; } \\
\text { - Luna cumpre poucas funções no cotidiano familiar, pois permanece maior } \\
\text { tempo na escola; } \\
\text { - De modo geral, nota-se que a divisão de tarefas é desigual, o que resulta em } \\
\text { sobrecarga de trabalho para Rosa. }\end{array}$ \\
\hline Afeto (affect) & $\begin{array}{l}\text { - A família demonstra troca de afeto, relação de cumplicidade e união; } \\
\text { - Rosa é carinhosa com toda família e faz com que esta se mantenha unida. }\end{array}$ \\
\hline $\begin{array}{l}\text { Comunicação } \\
\text { (communication) }\end{array}$ & $\begin{array}{l}\text { - Verificou-se que Rosa e os membros familiares expressam suas opiniões e } \\
\text { dialogam, sendo a comunicação compartilhada entre esses. No entanto, nota- } \\
\text { se dificuldade na comunicação, pois Rosa sendo porta-voz, muitas vezes } \\
\text { exerce poder dominante, determinando que sua vontade se sobressaia sob as } \\
\text { outras; } \\
\text { - A comunicação é prejudicada com o patriarca Luiz, pois pouco permanece no } \\
\text { lar. }\end{array}$ \\
\hline $\begin{array}{l}\text { T- Tempo no ciclo de vida } \\
\text { (time in life) }\end{array}$ & $\begin{array}{l}\text { - A família está inserida na etapa do ciclo de vida que abrange "Famílias com } \\
\text { adolescentes". }\end{array}$ \\
\hline $\begin{array}{l}\text { Doença no passado e no } \\
\text { presente (illness) }\end{array}$ & $\begin{array}{l}\text { - Rosa é portadora de HAS e depressão (padrão observado em gerações } \\
\text { anteriores); } \\
\text { - Luiz tem histórico de HAS; } \\
\text {-Luna e Liz são portadoras de transtorno de ansiedade generalizada. }\end{array}$ \\
\hline
\end{tabular}

Continua... 
...continuação

\begin{tabular}{|l|l|}
\hline $\begin{array}{l}\text { Lidando com o estresse } \\
\text { (coping with stress) }\end{array}$ & $\begin{array}{l}\text { Observou-se que a família se apoia em Rosa para enfrentar os momentos de } \\
\text { estresse e alguns membros fazem uso de psicofármacos para controlar } \\
\text { momentos de angústias e lidar com os sintomas depressivos e de ansiedade. }\end{array}$ \\
\hline $\begin{array}{l}\text { Ecologia ou Meio Ambiente } \\
\text { (environment/ecology) }\end{array}$ & $\begin{array}{l}\text { - A família sente falta de uma rede de suporte social, raramente recebe visitas } \\
\text { de amigos e não participa das atividades na comunidade, possuindo assim } \\
\text { pouca interação externa com o meio; }\end{array}$ \\
- Frequentemente procuram a ESF para cuidados de saúde se sentindo \\
acolhidos pela equipe.
\end{tabular}

Fonte: Elaborado pelos autores.

Conferência Familiar

A conferência familiar foi agendada e programada para ser realizada em um dia e horário que todos os membros da família estivessem presentes, fator imprescindível para que os objetivos do estudo fossem atingidos. Dessa forma, a reunião aconteceu com a presença da médica, enfermeira e dentista da ESF, além de todos os membros do núcleo familiar estudado.

A conferência iniciou-se com os cumprimentos e apresentação de todos os presentes, além de um breve resumo sobre o trabalho desenvolvido e seus propósitos. Em seguida, como resultados das etapas anteriormente executadas (montagem do genograma, aplicação do FIRO e P.R.A.T.I.C.E., além da identificação da fase do ciclo de vida da família) foram expostos de forma objetiva os problemas identificados pela equipe de saúde e discutidas propostas para a resolução dos mesmos. Os principais problemas observados foram: repetição de doenças crônicas como HAS, DM e depressão em várias gerações familiares; dificuldade de reinserção da paciente índice no mercado de trabalho; dificuldades para superação do ciclo de vida familiar; não compartilhamento de responsabilidades e decisões familiares com o esposo com o intuito de poupá-lo de preocupações; sobrecarga de trabalho de Rosa em relação aos cuidados com Bob.

Após exposição dos referidos problemas os membros familiares foram instigados a discutir e propor soluções para os mesmos. Todos concordaram com o levantamento feito e participaram ativamente com opiniões e sugestões sobre atos concretos a serem realizados com o objetivo de resolução dos problemas.

Assim, ficou estabelecido que:
A família alteraria alguns hábitos de vida, realizando atividade física regular (caminhada pelo menos $3 x /$ semana), alimentação mais saudável e Luiz irá amadurecer a ideia sobre cessar o tabagismo; além disso, permanecerá em acompanhamento na ESF para ações de promoção à saúde, prevenção e reabilitação da saúde.

$\checkmark$ Rosa faz uma forte associação da sua depressão, baixa autoestima e aparência física como fatores dificultadores do seu retorno ao mercado de trabalho. Como alternativas para esse problema ficou estabelecido que Liz será responsável em ajudar Rosa a criar uma rotina de cuidados de beleza através da incorporação de hábitos estéticos (escovar cabelo, fazer unha, maquiagem, escolha de roupas, etc.) que ajudem a melhorar sua autoestima e provocar mudanças na qualidade de vida. Além disso, Luiz entrará em contato com um colega responsável pela contratação de funcionários para uma nova unidade de uma rede de supermercados que abrirá na cidade para agendar entrevista para Rosa. Luna ficou com a função de ajudar Rosa na manutenção e divulgação em redes sociais de um Brechó virtual que ela decidiu abrir após as discussões que realizamos sobre essa alternativa de renda em nossos encontros. Por fim, Rosa se empenhará em realizar um tratamento adequado e seguir corretamente as orientações médicas sobre tratamento medicamentoso e psicoterápico para sua depressão.

$\checkmark$ Os empecilhos para a superação do ciclo de vida dizem respeito principalmente a 
uma superproteção materna em relação às filhas e ao sentimento de Liz de apego exagerado e responsabilização excessiva nos cuidados aos pais. Sobre esse tema ficou estabelecido que ambos, pais e filhas, discutirão mais frequentemente sobre suas responsabilidades e projetos de vida, de forma que não se prejudiquem ou não evitem mudanças essenciais para seguirem o fluxo normal do ciclo de vida familiar.

$\checkmark \quad$ No que diz respeito à postura de Rosa em poupar o marido dos acontecimentos cotidianos, ficou acordado que estes iriam praticar o diálogo, comunicar-se com mais efetividade e compartilhar responsabilidades, ainda que o Luiz esteja distante/viajando devido seu trabalho.

$\checkmark \quad$ A paciente índice refere que o problema quanto aos cuidados direcionados a Bob foram amenizados após a percepção da mesma em relação à capacidade do irmão em seguir em frente independente da dedicação e zelo ofertados por ela, como também compreendeu que suas atitudes impactavam negativamente o convívio familiar. Assim, relata que isso deixou de ser um problema. Os demais membros concordaram e relataram que a mudança de comportamento de Rosa em relação ao irmão melhorou substancialmente a convivência em casa.

Assim, após os membros terem sido ouvidos em relação a seus sentimentos e expectativas e ter sido feito um planejamento para a resolução dos problemas identificados, foram ressaltados vários pontos positivos da família (união, amor, cumplicidade, etc.) além da importância do desempenho adequado dos papeis familiares para o sucesso terapêutico desejado.

Por fim, a equipe agradeceu a família por terem aceitado e ajudado no desenvolvimento desse estudo a reforçou os laços e vínculos colocando-se à disposição para ajudar nas demandas necessárias.

\section{Resultados e Discussões}

A equipe multiprofissional da Estratégia de Saúde da Família, muitas vezes vivencia situações em que o modelo biomédico e centrado na patologia em si não é suficiente para o cuidado necessário. Nesse contexto, a abordagem familiar juntamente com a utilizações dos instrumentos facilitam a compreensão de alguns agravos a saúde. Quando se busca conhecer as particularidades do sujeito, bem como seus problemas, o profissional de saúde deve se corresponsabilizar por seu cuidado, permitindo e fornecendo informações para que esse indivíduo e família adquira autonomia e empoderamento para construir sua saúde. Cuidar do individuo é acolher sua família, respeitando seus valores e crenças $^{11}$.

No que tange as doenças de maior prevalência na família da paciente índice, se destacam a DM, HAS e depressão. As doenças crônicas degenerativas ou não transmissíveis (DCNT) constituem um sério problema de saúde pública, sendo responsáveis por $63 \%$ das mortes no mundo ${ }^{12}$. No Brasil, essas doenças são responsáveis por mais de $70 \%$ das mortes ${ }^{13}$.

Destaca-se ainda, que a depressão presente nos indivíduos farmacodependentes interferem nas relações familiares ${ }^{14}$. Sendo assim, a família passa a ter um papel muito importante tornando-se capaz de superar os problemas de saúde e adotar recursos que melhorem o seu comportamento, contribuindo assim, para que o autocuidado se torne efetivo ${ }^{15}$.

Ao aplicar as ferramentas de abordagem familiar, verificou-se que a família se encontra na fase em que os filhos teriam que deixar a casa paterna para serem independentes. Nesse momento é necessário que os membros aceitem as saídas e entradas de indivíduos no sistema familiar, ao passo que a casa precisa renegociar o sistema conjugal como par. É preciso, ainda, que ocorra mudanças no relacionamento entre pais e filhos ${ }^{16}$.

No que concerne à comunicação familiar, este é um fator essencial e indispensável dentro da família, recebendo ainda mais importância e responsabilidade na fase adolescente, já que os filhos estão em constantes transformações, e em contato com diversas informações recebidas do meio externo ${ }^{17}$.

A reinserção da paciente índice no mercado de trabalho se apresenta como fator desencadeador para a atual situação da família. Além do ganho e independência financeira, o sentido do trabalho para indivíduos e grupos hoje é um passo essencial para compreender o comportamento das pessoas no trabalho num mundo pós-moderno, no qual a dimensão profissional ainda tem papel fundamental para a formação da identidade e para o bem-estar das pessoas $^{18}$. 
A conferência, como proposta de intervenção neste estudo mostrou-se efetiva, pois oportunizou aos membros da família colocarem-se diante dos problemas de forma reflexiva, tornando a comunicação mais clara e a distribuição de papeis mais adequada. Nesse sentido, em concordância com outros estudos a conferência tem sido determinante em trabalhos com famílias em situações de agravos à saúde ${ }^{19-20}$.

\section{Conclusão}

O desenvolvimento desse estudo com a aplicação das ferramentas de abordagem familiar possibilitou uma compreensão maior do contexto e dinâmica familiar, identificando fatores de risco importantes para a saúde de seus membros. Além disso, permitiu aos membros da família realizarem um exercício de autorreflexão sobre seus papeis e sua importância no funcionamento familiar. Com isso, pode-se observar um maior fortalecimento de vínculos e clareza na determinação das funções de cada membro para uma melhor qualidade de vida da família.

Esse trabalho mostrou-se relevante ao evidenciar que o conhecimento da dinâmica familiar é fundamental para uma intervenção personalizada e capaz de fornecer maior qualidade de vida à família, além de oferecer um serviço integral e de qualidade aos seus usuários, o que não seria possível com o uso do modelo biomédico de assistência à saúde.

O estudo da família possibilitou ainda o fortalecimento de vínculos da equipe e esses usuários, o que favoreceu uma maior eficácia da intervenção, além de aumentar a confiança e satisfação tanto da família atendida quanto da equipe que executou a proposta.

\section{Referências}

1. Silva MCLSR, Silva L, Bousso R. A abordagem à família na Estratégia Saúde da Família: uma revisão integrativa da literatura. Rev Esc Enferm USP. 2011; 45 (5): 1250-1255. [Citado 2019 fev 26]. Disponível em: http://www.scielo.br/pdf/reeusp/v45n5/v45n5a 31.pdf.

2. Matumoto S, Mishima SM, Fortuna CM, Pereira MJB, Almeida MCP. Discussão de famílias na estratégia saúde da família: processo de trabalho em construção. Rev Esc Enferm USP. 2011; 45 (3): 603-610. [Citado 2019 fev 26]. Disponível em: http://www.scielo.br/pdf/reeusp/v45n5/v45n5a 31.pdf
3. Chapadeiro CA, Andrade HYSO, Araújo MRN. A família como foco da Atenção Primária à Saúde. Núcleo de Educação em Saúde Coletiva NESCON/UFMG. Belo Horizonte. 2011.

4. Queiroz LS, Nobre L, Mendes P, Matos F, Soares $A$, Leão $C D$. Abordagem familiar no âmbito da estratégia saúde da Família: uma experiência de cuidado interdisciplinar. Revista da Universidade Vale do Rio Verde, Três Corações. 2014; 12 (2): 458-468. [Citado 2019 fev 26]. Disponível em: http://periodicos.unincor.br/index.php/revistaun incor/article/view/1488/pdf_227.

5. Brito GEG, Mendes ACG, Neto, PMS. O objeto de trabalho na Estratégia Saúde da Família. Interface: comunicação, saúde e educação. 2018; 22 (64): 77-86, 2018. [Citado 2019 fev 26]. Disponível em: http://www.scielo.br/scielo.php?pid=S141432832017005015101\&script=sci_abstract\&tlng=p t.

6. Santos KKF, Figueiredo CR, Paiva KM, Campolina LM, Barbosa AAD, Santos ASF. Ferramentas de abordagem familiar: uma experiência do cuidado multiprofissional no âmbito da estratégia saúde da família. Revista da Universidade Vale do Rio Verde, Três Corações. 2015; 13 (2): 377-387. [Citado 2019 mar 16]. Disponível em: http://periodicos.unincor.br/index.php/revistaun incor/article/view/2340/pdf_385

7. Nascimento LC, Dantas IRO, Andrade RD; Mello DF. Genograma e ecomapa: contribuições da enfermagem brasileira. Texto Contexto Enferm. 2014; 23 (1): 211-20. [Citado 2019 mar 16]. Disponível em: http://www.scielo.br/pdf/tce/v23n1/pt_01040707-tce-23-01-00211.pdf

8. Moysés ST, Kriger L, Moysés J. Organizadores. Saúde bucal das famílias: trabalhando com evidências. São Paulo: Editora Artes Médicas. 2008; 308 pp.

9. Silveira $A D$, Ducci $L$, Simão $M G$. Os dizeres da boca em Curitiba: boca maldita, boqueirão, bocas saudáveis. Centro Brasileiro de Estudos de Saúde (CEBES). 2002; 199 p. [Citado 2019 mar 16]. Disponível em: http://bvsms.saude.gov.br/bvs/publicacoes/livro _curitiba.pdf

10. Galriça NI. A conferência familiar como instrumento de apoio à família em cuidados paliativos. Revista Portuguesa de Clínica Geral. 2003; 19 (1): 68-74. [Citado 2019 mar 16]. Disponível em: http://www.rpmgf.pt/ojs/index.php/rpmgf/articl e/view/9906/0 
11. Brasil. Ministério da Saúde. Secretaria de Vigilância em Saúde. Caderno de Atenção domiciliar. Brasília Distrito Federal. 2013; 2(1): 1. [Citado 2019 mar 16]. Disponível em: http://189.28.128.100/dab/docs/geral/sad_vol2_ cap2.pdf

12. WHO. World Health Organization. United Nations high-level meeting on noncommunicable disease prevention and control. New York, 2011. [Citado 2019 mar 16]. Disponível em: https://www.who.int/nmh/events/un_ncd_sum mit2011/en/

13. IBGE. Instituto Brasileiro de Geografia e Estatística. Pesquisa Nacional de Saúde 2013: percepção do estado de saúde, estilos de vida e doenças crônicas. Rio de Janeiro, 2013. [Citado 2019 mar 16]. Disponível em: https://ww2.ibge.gov.br/home/estatistica/popul acao/pns/2013/.

14. Silva JL, Macedo RMS, Derntl AM, Bergami NBB. Um estudo das relações interpessoal em família com farmacodependentes. Psicologia em estudo. 2007; 12 (1): 61-70. [Citado 2019 mar 16]. Disponível

http://www.scielo.br/scielo.php?script=sci_abstr act\&pid=S1413-

$73722007000100008 \& \operatorname{lng}=e n \& n r m=i s o \&$ t $n g=p t$

15. Santin G, Klafke TE. A família e o cuidado em saúde mental. Barbaroi [online] 2011; 34(1): 146-160. [Citado 2019 mar 16]. Disponível em:

http://pepsic.bvsalud.org/scielo.php?script=sci_a bstract\&pid=S0104-

65782011000100009\&lng=es\&nrm=iso

16. Carter B, Mcgoldrink M. As mudanças no ciclo de vida familiar: Uma estrutura para a terapia familiar. 2ª . Porto Alegre: Artes medicas; 1995.

17. Morgado LV. Ciclo vital da família: a comunicação entre pais e filhos na fase adolescente. III Congresso Internacional de Ciência, Tecnologia e Desenvolvimento 20 a 22 de outubro de 2014. Ciência e tecnologia para o desenvolvimento social. [Citado 2019 mar 16]. Disponível em: http http://www.unitau.br/files/arquivos/category_1 54/MPB1488_1427286040.pdf

18. Cavazotte FSCN, Lemos AHC, Viana MDA. Novas gerações no mercado de trabalho: expectativas renovadas ou antigos ideais?. Cadernos EBAPE.BR. 2012; 10 (1): 162-180. [Citado 2019 mar 16]. Disponível em: http://www.scielo.br/scielo.php?pid=S1679$39512012000100011 \&$ script $=$ sci_abstract $\&$ tlng $=p$ $\mathrm{t}$
19. Tonelli SQ, Oliveira RFR, Lopes MC, Alencar AM, Rodrigues LAM. Compreensão da dinâmica familiar no processo saúde-doença e intervenção pela equipe de saúde da família: um estudo de caso. Revista Norte Mineira de Enfermagem. 2016; 5 (1):74-84. [Citado 2019 mar 16]. Disponível em: http://www.renome.unimontes.br/index.php/re nome/article/view/125

20. Brante ARSD, Martins DS, Neves FMV, Fonseca JD, Ottoni JLM, Oliveira RFR. Abordagem Familiar: aplicação de ferramentas a uma família do município de Montes Claros/MG. Rev Bras Med Fam Comunidade. 2016; 11 (38): 1- 9.

\section{Endereço para Correspondência}

Av. Prof. Rui Braga, S/N - Vila Mauriceia, Montes

Claros - MG

CEP.: 39401-089

e-mail: paloma11natal@hotmail.com

Recebido em 16/04/2019

Aprovado em 05/12/2019

Publicado em 12/02/2020 